\title{
A revolução dos cravos e o controlo operário
}

\author{
Raquel Varela ${ }^{1}$ \\ https://orcid.org/0000-0001-6121-1379
}

\author{
Jorge Fontes ${ }^{2}$ \\ https://orcid.org/0000-0003-3567-2731
}

${ }^{1}$ Universidade Nova de Lisboa, Faculdade de Ciências Sociais e Humanas, Instituto de História Contemporânea, Lisboa, Portugal

${ }^{2}$ Universidade Nova de Lisboa, Faculdade de Ciências Sociais e Humanas, Instituto de História Contemporânea, Lisboa, Portugal

\section{A revolução dos cravos e o controlo operário}

Resumo: Neste artigo argumentamos que a característica fundamental da revolução portuguesa de 1974/75 é a luta sociológica de classes sociais travada dentro das empresas e, sobretudo, nas grandes unidades industriais. Defendemos, no âmbito de uma revisão da literatura, dever essa disputa definir-se como controlo operário, distinguindo-o quer do seu contrário - o controlo da produção, ou seja, estatalnacional - quer de formas de cogestão ou autogestão, as quais aparecem frequentemente misturadas.

Palavras-chave: Revolução dos Cravos. Controlo Operário. Autogestão.

\section{The carnation revolution and workers' control}

Abstract: In this article we argue that the fundamental feature of the 1974/75 Portuguese revolution is the sociological struggle of social classes within companies and, above all, in large industrial units. We argue, in the context of a literature review, that this dispute should be defined as workers' control, distinguishing it from its opposite - production control, that is, state-national control - or from forms of co-management or self-management, which often appear mixed.

Keywords: Carnation Revolution. Workers' Control. Self-management

Recebido em 12.07.2019. Aprovado em 11.02.2019. Revisado em 31.03.2020.

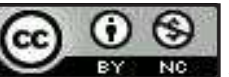

(C) O(s) Autor(es). 2020 Acesso Aberto Esta obra está licenciada sob os termos da Licença Creative Commons Atribuição-NãoComercial 4.0 Internacional (https://creativecommons.org/licenses/by-nc/4.0/deed.pt_BR), que permite copiar, distribuir e reproduzir em qualquer meio, bem como adaptar, transformar e criar a partir deste material, desde que para fins não comerciais e que você forneça o devido crédito aos autores e a fonte, insira um link para a Licença Creative Commons e indique se mudanças foram feitas. 


\section{Introdução}

Portugal viveu a última revolução social de esquerda na Europa durante o século XX, um processo aberto pelo golpe de estado do 25 de abril de 1974 e encerrado com outro golpe, a 25 de novembro de 1975. Após meio século de revoltas fracassadas da oposição democrática, um golpe militar de capitães organizados no Movimento das Forças Armadas (MFA) descontentes com a ausência de uma solução política para a guerra colonial, obtém sucesso ao ser esmagadoramente apoiado pela população urbana da capital que sai à rua cercando o quartel onde se refugiara o ditador Marcelo Caetano.

Este artigo aborda o processo revolucionário sob um ângulo ainda negligenciado da investigação académica, o controlo operário. Com efeito, com a entrada em cena, na escala dos milhões, das massas proletarizadas, o golpe transmuta-se em revolução. A exigência de afastamento dos elementos ligados ao antigo regime transforma uma dinâmica democrática e antifascista, numa progressiva luta pelo controlo das empresas, objetivamente anticapitalista.

Espalhando-se como uma mancha de óleo, surgem organismos de tipo conselhista típicos da onda revolucionária de 1917-23, como os Comités de Fábrica na Rússia ou os Conselhos Operários de Turim: em Portugal vão em regra chamar-se Comissões de Trabalhadores (CTs) que, ao contrário dos sindicatos, reúnem todos os trabalhadores da mesma unidade económica independentemente da profissão, sendo normalmente constituídas após assembleias gerais amplamente participadas, mantendo uma ligação à base mais direta devido à sua fácil revogabilidade e inserção num processo de massas.

O objetivo deste artigo passa por demonstrar que a revolução propriamente dita, mais do que ser definida por complots militares, querelas partidárias, biografias dos grandes líderes, deve ser analisada pelo prisma do movimento "de baixo" (ZINN, 2005) deste bloco social. Ela é ditada por necessidades práticas. Será para manter os postos de trabalho ameaçados pela crise económica e frequentemente pela sabotagem económica patronal - que numa luta económica os trabalhadores ocupam as empresas, vendo-se obrigados a continuar a laboração em processos autogestionários nas unidades médias e pequenas, ou - algo mais difícil de medir por implicar uma análise qualitativa da relação de forças, a adotar formas de vigilância e controlo da atividade produtiva e do circuito comercial nas maiores unidades, mais complexas, nas quais é mais curial o peso dos engenheiros e quadros técnicos, ou seja: o controlo operário.

A nossa escolha não é arbitrária - pode-se fazer a história dos Governos a partir dos decretos e das lutas políticas entre as frações do Governo, acrescentando a descrição das lutas sociais. Pode-se fazer a história do controlo operário nas principais fábricas e empresas do País - com reminiscências em todas as centenas e milhares de empresas satélites destas (numa indústria com alto grau de monopolização) - e ver como estas mudanças vai comprometer a própria estabilidade dos seis governos provisórios.

A opção não é livre. Teoria e metodologia no labor da história não podem ser dispensadas nem por uma visão positivista que encadeia acontecimentos, nem pelo irracionalismo relativista pós-moderno que escolhe arbitrariamente os factos. Não é a crise política que dá origem ao controlo operário. É a luta nas empresas e fábricas que determina a crise política, que por sua vez vai ter impacto no controlo operário. Não há uma mera correlação, há uma relação causal. O controlo operário é assim um conceito determinante na análise e interpretação da história da revolução.

Este artigo encontra-se dividido do seguinte modo: a esta introdução segue-se uma seção que trata de fazer um estado da arte e revisão da literatura dos debates sobre o controlo operário. $\mathrm{O}$ item seguinte trata de analisar a sua evolução em diferentes fases, durante os nove meses da revolução. Posteriormente analisamos diferentes casos de estudo de empresas nas quais se desenrolaram processos de controlo operário. Na seção seguinte, abordamos as diferentes tentativas de unificação do controlo operário em estruturas de coordenação em nível nacional. Por fim, apresentamos breves conclusões.

\section{Os debates sobre o controlo operário}

Na literatura sobre o tema tem sido frequente a confusão entre controlo operário e autogestão, cogestão (que inclui os sindicatos) e também com situações de duplo poder organizado (sovietes). O controlo operário é um dos temas mais interessantes, mas menos estudados do período revolucionário em Portugal. É um paradoxo evidente, porque haver controlo operário faz parte da definição de um período como revolucionário.

Há poucos períodos na história onde este tema possa ser desenvolvido com a riqueza histórica da dimensão a que chegou este controlo no biénio 1974-1975 em Portugal. Casos semelhantes podem ser encontrados no biénio vermelho em Itália em 1919-20 (HARMAN, 2002) ou nas revoluções russas de 1905 e 1917 (TROTSKY, 1980), e por exemplo, mais recentemente, nos cordões industriais chilenos de 1972-1973 (WINN, 1986). 
"Um burguês só está derrotado quando foge", escreveu o historiador C. L. R. James na sua monumental obra Jacobinos Negros, que conta a história da revolução que deu origem ao Haiti (JAMES, 2000). Em Portugal, durante 1975, atinge-se esse momento raro na história em que setores da classe dominante literalmente fugiram do País e outros viram-se sequestrados nas empresas que outrora administravam.

A escassez de obras sobre o tema do controlo operário bem como a migração da história da esfera económica, social e política para o âmbito político-institucional geraram uma confusão à volta do conceito de controlo operário, com poucos paralelos na historiografia social. É difícil encontrar um autor que use o mesmo nome para coisas idênticas. Pelo reverso, usa-se sobre coisas distintas, indiscriminadamente, o conceito de controlo operário. Ele é sobretudo confundido com autogestão, mas também, no caso da revolução portuguesa, com cogestão, intervenção do Estado nas empresas, ocupação de fábricas e empresas, processos reivindicativos de cariz sindical, democracia industrial e mesmo com a própria gestão do Estado.

O controlo operário é um processo de dualidade de poderes que consiste na organização política dos trabalhadores ao nível da produção - formalizada ou não - com tendência (objetiva) à tomada do poder político. É uma situação no processo de luta no meio de um processo revolucionário e não uma estrutura ou instituição. Haver controlo operário é parte da definição do próprio conceito de um período como sendo revolucionário. Este fenómeno específico distingue-se da autogestão (forma em que os trabalhadores passam a ser patrões de si próprios) e da cogestão (os trabalhadores estão, normalmente através dos sindicatos, a gerir a empresas e/ou fábricas em parceria com os patrões e/ou com o Estado).

É comum ver também em algumas obras a associação entre controlo operário e situações de duplo poder organizadas, não reconhecendo estes autores a existência de controlo operário por não existirem formas de organização conselhistas estruturadas (sovietes). Cremos que esta visão é equivocada porque em determinadas situações o controlo operário pode ser mais forte que a dualidade de poderes a nível político, ou seja, a disrupção na produção no setor económico pode ser muito mais extensa do que a crise do Estado. Foi esse o facto que se verificou na revolução portuguesa, mas também em outros processos de controlo operário como com os cordões industriais chilenos ou os conselhos no biénio vermelho italiano.

Na década de 70 do século XX o controlo operário era amplamente debatido, a partir das experiências de 1968 (BRINTON, 1975; MANDEL, 1975; HAMMOND, 1981). Foi, porém, a teoria produzida pelos dirigentes revolucionários entre as revoluções de 1848 e a década de 30 do século XX - Karl Marx (2011), Lenine (1976), António Gramsci (1921), Karl Korsch (1929), Leon Trotsky (1931), Pannekoek (1977), Adler (1976) que aprofundou este debate.

Como não existe, contudo, um corpo teórico de síntese dedicado a esta questão, deixamos em resumo as principais escolas de pensamento e debate teórico.

Karl Marx (2011), a partir da experiência histórica da Comuna de Paris, em 1871, desenvolve esta questão dando importância às experiências de gestão dos trabalhadores, mas apontando não para uma defesa da autogestão - a qual só existia realmente depois de o proletariado tomar o poder, o que então denominou numa famosa frase, o autogoverno dos produtores, - mas para o papel que a autogestão podia ter na aprendizagem, na experiência que poderia dar aos operários.

Durante o movimento de ocupações de fábrica de 1919-20 em Turim, o projeto de regulamentação do controlo operário do primeiro-ministro Giovanni Giolitti é contestado por Gramsci (1921) como uma ingerência do parlamento nacional e do "poder burguês" naquilo que deve ser a luta da classe operária de modo autónomo pela criação de um Conselho Nacional:

Para os comunistas, pôr o problema do controlo significa [...] pôr o problema do poder operário sobre os meios de produção, o problema da conquista do Estado. [...] Toda a lei sobre isso que emane do poder burguês tem um único significado e um único valor: significa que realmente, e não só verbalmente, o terreno da luta de classes mudou, na medida em que a burguesia é obrigada, neste novo terreno, a fazer concessões e a criar novos institutos jurídicos; e tem o valor demonstrativo real de uma debilidade orgânica da classe dominante.

Também Trotsky (1931), o primeiro presidente de um soviete (na Rússia em 1905), ao discutir a situação dos concelhos de fábrica legais alemães argumenta que estes não poderão ser órgãos de controlo operário sob a legalidade existente e fora de uma situação de "duplo poder":

Nunca escrevi conselhos de fábrica "legais". E não só apontei inequivocamente que os conselhos de fábrica só podem se tornar em órgãos de controlo operário sob a premissa de uma tal pressão da parte das massas que pelo menos parcialmente no país e nas fábricas já foi estabelecida uma situação de duplo poder. É para mim claro que os conselhos de fábrica podem sob a lei atual tornar-se tanto em órgãos de controlo operário como a revolução dar-se no quadro da constituição de Weimar! 
O revolucionário russo levanta uma questão que nos parece central para explicar a revolução portuguesa: que em determinadas situações o controlo operário pode ser mais forte que a dualidade de poderes a nível político.

Um regime avançado de dualidade de poder, como uma das etapas altamente prováveis da revolução proletária em todos os países, pode se desenvolver de forma diferente em diferentes países, a partir de elementos diversos. Assim, por exemplo, em certas circunstâncias (uma crise económica profunda e persistente, um forte grau de organização dos trabalhadores nas empresas, um partido revolucionário relativamente débil, um Estado relativamente forte mantendo um fascismo vigoroso em reserva, etc.), o controlo operário sobre a produção pode ir consideravelmente à frente do poder político dual desenvolvido num país.

Lenine (1976, p. 61-65), responsável pelo primeiro decreto sobre controlo operário no mundo situa o controlo operário no contexto da nacionalização da banca e grandes unidades industriais e comerciais. $\mathrm{O}$ seu projeto de decreto-lei de 9 de novembro de 1917 estabelece o controlo operário "sobre a produção, conservação e compra-venda de todos os produtos e matérias-primas, em todas as empresas industriais, comerciais, bancárias, agrícolas", sendo este exercido diretamente pelos operários e empregados nas pequenas empresas ou por representantes eleitos em assembleias gerais, e assinalando-se que "sem abolir o segredo comercial, o controlo da produção e da distribuição não iria mais longe que uma promessa vazia".

A discussão sobre o controlo operário estende-se evidentemente à forma organizativa que lhe dava sustento, organizada ou espontânea: os conselhos. Anton Pannekoek $(1952$, p. 1) é dos autores que mais discutem esta questão, ao referir-se à democracia do trabalho, argumentando que o "controlo direto da produção pelos trabalhadores significa que os empregados dirigem as empresas e constroem os organismos centrais desde abaixo", opondo ao "estatismo socialista" um "sistema de conselhos operários".

Karl Korsch (2011, p. 32) desenvolve o conceito de democracia industrial, opondo-se à ideia de luta pelo poder do Estado. Para este autor, a luta em última instância decisiva é a travada pelo domínio da economia (ou da "organização do trabalho"), e não a disputa pelo controlo dos órgãos dirigentes do Estado.

Para alguns autores, como Mattick (1977, p. 27), o controlo operário exclui a colaboração de classes; não pode tomar parte no sistema de produção capitalista, mas em vez disso, suprime-o, deste modo nunca existiu. No espectro oposto Nancy Bermeo (1986) estende o conceito ao movimento rural de ocupações de terras, sem preocupações de definição conceitual e teórica.

Em Portugal, em 1974-75, usava-se controlo operário indefinidamente para participação na gestão, publicidade dos vencimentos e controlo sobre a produção.

Brinton (1975, p. 14) argumenta que a confusão é em parte uma questão de palavras, pois em Inglaterra é raro distinguir com clareza "controle" e "gestão", enquanto na literatura política francesa, espanhola ou russa, dois termos diferentes (contrôle e gestion, control e gestión, kontrolia e upravleniye) designam respetivamente uma dominação parcial ou total dos produtores no processo de produção.

A palavra "controlo" (ou "controle", como se usa mais frequentemente na altura) tem origem no francês contrôle, significando verificação de dados, de informações, averiguação sobre o cumprimento de certas normas, fiscalização, inspeção, uma distinção subtil mas significativa da expressão "controlar", também proveniente do francês contrôler, ou seja ter o poder sobre alguma coisa, tomando todas as decisões importantes sobre o seu funcionamento ou atividade, exercer o controle, administrar (CASTELEIRO, 2001, p. 958).

Contudo, argumentamos que se trata, mais do que uma questão linguística, de uma disputa política que joga com a ambiguidade do termo. As organizações políticas e sindicais batalhavam para que a expressão controlo operário adquirisse significados diferentes consoante a estratégia política. Estes conceitos entrelaçam-se e atropelam-se porque a luta política, nas fábricas e empresas, evoluiu de forma igualmente intrincada. Quase dia a dia várias empresas podiam passar de um estágio de conflito democrático (perseguição do informador da polícia política) para um de ocupação, o Estado intervir nessa empresa e pouco depois ela ficar em autogestão, ou a autogestão começar antes da intervenção, e mais tarde, ou antes, a questão do controlo operário ter sido colocada, e logo depois evoluir-se nessas fábricas para propostas de ligação embrionária do controlo dessa fábrica a outras do mesmo ramo ou setor.

Sendo ainda possível, até provável, que nessa mesma empresa ou fábrica, para manter o exemplo, se tenha travado uma luta política diária entre os que defendem a manutenção da propriedade e/ou controlo do Estado, uma "batalha da produção" e formas de cogestão; os que acreditam na autogestão e desenvolvem mecanismo técnicos de controlo da produção, mas à margem da política da "batalha da produção"; e os que, num processo de controlo operário, procuram um enquadramento nacional e político de controlo das empresas que imponha a disrupção total do Estado. 


\section{Evolução do controlo operário}

Com algumas exceções, pode sistematizar-se um modelo analítico em que a história do controlo operário na revolução se divide essencialmente em três grandes períodos: 1) formas atomizadas; 2) controlo operário coordenado por setor; 3) controlo operário disseminado a nível nacional e coordenado embrionariamente a nível distrital e nacional, mas com divisão política e partidária e sem centralização.

Nas lutas sociais, a partir de 25 de abril de 1974, existe controlo operário em formas de protesto radicais (greves, sequestros, ocupações) sobretudo ao nível da luta que força as administrações a mudarem a sua composição (saneamentos). Nesta fase, o controlo operário é atomizado, o centro é a empresa - e não o poder político estatal -, a luta é pela recomposição da administração e não pelo controlo da produção na totalidade, e não há coordenação nacional destas formas de ação coletiva, nem sequer embrionária.

Existem vários processos autogestionários que se distinguem do controlo operário por defenderem a propriedade da empresa nas mãos dos próprios trabalhadores (COMISSÃO COORDENADORA..., 1981). O controlo operário amplia-se, mas é limitado a alguns setores como nos transportes aéreos (TAP), os estaleiros navais Lisnave, Jornal do Comércio, um quadro restrito no panorama nacional.

Movidos por interesses de ordem democrática (garantia das liberdades), os trabalhadores vão organizarse em assembleias que elegem Comissões de Trabalhadores, que ao contrário dos sindicatos, unificam todos os trabalhadores da empresa, independentemente da sua profissão. A unificação das reivindicações democráticas com as económicas e políticas vai determinar uma evolução da consciência política, pela incapacidade do regime, num quadro de profunda recessão, de evitar o crescente desemprego (ROSA, 1975).

\section{O controlo operário é um}

\section{processo de dualidade de}

poderes que consiste na

organização política dos

trabalhadores ao nível da

produção - formalizada ou não

- com tendência (objetiva) à

tomada do poder político.

Surge assim, numa segunda fase, a partir de fevereiro de 1975, o controlo operário, uma situação de luta política e questionamento do poder do Estado, organizado na base da fábrica ou empresa, para conseguir concretizar as reivindicações económicas. Este é aliás, argumentamos, um dos fatores que explicam a nacionalização da banca. No caso português não se limitou a haver uma nacionalização da banca, mas sim uma expropriação, porque esta é realizada sem indemnizações.

Abre-se uma luta política dentro das empresas, sobretudo a partir de maio de 1975, entre os que se organizam no sentido de exercer o controlo operário, a partir de comissões de controlo sobre toda a produção (incluindo lucros e salários) com vista a "tomar o poder pelos trabalhadores" (posição que será possante ou dominante em muitas fábricas) e que por isso colocam a tónica organizativa na coordenação nacional das comissões de controlo, por setor, com as empresas satélites; e um outro grupo de trabalhadores - onde se enquadram os dirigidos pelo Partido Comunista Português (PCP) e pelo arco governativo - que se coloca numa posição de defesa da cogestão entre administrações, trabalhadores e Estado, ou entre Estado e trabalhadores, e que tende a colocar a tónica na defesa da "economia nacional", na "batalha da produção", e rejeita o controlo sobre salários, por exemplo, bem como a nacionalização de empresas com capital estrangeiro.

A crescente plausibilidade de uma derrota para a burguesia portuguesa, a constituição de um "soviete" nacional, uma coordenadora nacional das comissões de trabalhadores, que se configuraria como um poder alternativo nacional, um contrapoder ao Estado (e como tal ficará escrito nos documentos de plenários de diversas empresas), liderado pelo operariado industrial fortemente concentrado em três cidades (Lisboa, Porto e Setúbal), irá levar a várias tentativas governamentais de frear este processo.

É neste contexto que no Conselho Económico do IV Governo Provisório, a 7 de maio de 1975, o secretário de Estado do Trabalho, Carlos Carvalhas, membro do PCP, apresenta um projeto de decreto-lei relativo ao controlo operário, pretendendo subordinar os órgãos políticos dos trabalhadores ao Estado.

Considerando-se a "urgente necessidade de reconhecer o direito ao controlo organizado da produção" (i.e. verificando-o como um a priori factum), postula-se que o mesmo "não deverá conduzir ou contribuir para entravar a normal atividade produtiva da empresa, bem como interferir no exercício de funções de natureza administrativa cometidas aos órgãos competentes". As CTs só podem exercer o controlo operário nas empresas existentes onde já o faz, nas novas a incumbência é remetida às comissões sindicais ou delegados sindicais. As tarefas dos órgãos de controlo são limitadas a "emitir parecer e garantir a execução" dos "planos gerais da 
empresa"; "contribuir para a melhoria quantitativa e qualitativa da produção", "velar pelo cumprimento dos programas do Governo" e garantir "o cumprimento rigoroso de medidas de austeridade económica que o Governo adote" (PATRIARCA, 1976a, p. 768-769).

No jornal do PCP, o Avante! faz-se a defesa desta política: criação de comissões de controlo destinadas a garantir "a vitória da batalha da produção" (AVANTE!, 1975a, p. 4). Reúne um amplo consenso na coligação, no Conselho da Revolução e no Movimento das Forças Amadas (MFA). O Partido Socialista (PS) e o Partido Popular Democrático (PPD) declaram que a situação difícil exige contenção das reivindicações e que "o poder político passa pela batalha da produção" (DIÁRIO DE LISBOA, 1975, p. 1).

Mas há um debate dentro de setores minoritários do Governo contra esta estratégia. Em alternativa, apresenta-se um outro documento, elaborado pelo secretário de Estado da Indústria, João Martins Pereira, um intelectual marxista independente, com um projeto menos estatista que aumenta a margem de autonomia dos órgãos de controlo dos trabalhadores. Define o controlo da produção como uma ação, por parte dos "próprios trabalhadores, tendente a assegurar que a unidade produtiva (ou setor) em que se inserem está a ser utilizada da forma mais adequada, tendo em visto o esforço coletivo global no sentido da instauração de uma sociedade socialista". Defende-se que assembleias gerais de trabalhadores elejam "comissões de controlo da produção", ou atribuam à CT ou comissão sindical já existente (ou a parte delas) essa incumbência. Pretendia deste modo, evitar os "conhecidos inconvenientes de uma estatização de cima para baixo" e "obstar a pragmáticas motivações de "reconstrução nacional" que adiam a revolução para quando ela estiver terminada (a exemplo do que sucedeu nos países europeus ocidentais no pós-guerra)" (PATRIARCA, 1976a, p. 766-792).

Durante a revolução nenhum projeto ou plano de coordenação e controlo chegou a ser concretizado. Estes pretendiam integrar os órgãos dos trabalhadores no aparelho de Estado, que detém a soberania máxima. $\mathrm{Na}$ nossa tese trata-se de um fenómeno oposto ao pré-existente controlo operário, pois este exprime um conflito sociológico entre o trabalho e o patronato/Estado.

A incapacidade da coligação de governo em controlar a agitação social conduzirá à sua rutura, e também à do MFA, no verão de 1975. A questão do controlo operário - situada ao nível das empresas e bairros estende-se, depois de setembro de 1975, ao Exército, aos quartéis. O MFA tentava, sem sucesso, equilibrar e evitar o choque; quando se desmembra, uma parte dos seus membros fica com a direita, mas uma parte da esquerda militar, com posições em setores chave das forças armadas, tenderá a apoiar formas, muito embrionárias, de duplo poder (comissões de soldados), o que conduz a choques dentro do PCP, cuja maioria da sua direção, apostava nos reequilíbrios de tipo frentista com o PS.

Este último período caracteriza-se assim pela paulatina construção de formas embrionárias de coordenação de controlo operário em nível nacional, com especial realce para a formação de um embrião de soviete na região de Setúbal, o Comité de Luta, unificando empresas, comissões de moradores e de soldados (COSTA, 2017).

Contudo, a recuperação de forças pela direita e o PS no governo e nas Forças Armadas, conjugada com a impotência do movimento operário em se centralizar e desenvolver uma alternativa programática independente que o atrela aos projetos de controlo emanados do aparelho de Estado, aos planos castrenses e às disputas partidárias vai selar o fim do processo revolucionário.

\section{Casos de estudo}

Como vimos, o controlo operário evoluiu a partir de fevereiro de 1975. Nas empresas nacionalizadas, nas principais empresas de metalomecânica e mesmo noutros setores entra-se numa situação de controlo operário para além da autogestão, mais estabelecida nas pequenas empresas e nas empresas em reais dificuldades financeiras e/ou produtivas. Este tipo de discussão é levado a cabo - de forma polémica - em todos as principais empresas. Na Sociedade Central de Cervejas, em maio de 1975, aprova-se o seguinte documento (PATRIARCA, 1976b, p. 1056-1057):

Mas sempre esclarecendo que as chefias se mantêm plenamente responsabilizadas e pagas para fazer a gestão. O controlo operário não vem resolver todos os problemas dos trabalhadores. Não resolve o problema do pão, dos salários e do emprego dos trabalhadores. São necessárias outras formas de organização que levem os trabalhadores à tomada do poder. Mas o controlo operário permitirá aos trabalhadores:

a) Precaverem-se das tentativas de sabotagem económica.

b) Prepararem-se progressivamente para a tomada do poder político.

Na SAPEC, uma empresa de adubos de capital belga, com 1000 trabalhadores, desenvolve-se uma luta com ocupação das instalações contra a vontade da administração transferir dividendos para a sede 
em Bruxelas, o que punha em causa o pagamento dos vencimentos. Entrevistados pelas câmaras da televisão, os trabalhadores lembram com orgulho que durante a ocupação a empresa nunca parou, é a segunda no país no setor dos adubos, em pesticidas é a primeira, labora na produção de rações, vende e produz viveiros de árvores de frutos, sementes e tratamentos aéreos O jornalista pergunta a um trabalhador qual o resultado da recente reunião com o Governo e a resposta é lapidar: "Ganhámos, não é de admirar que tivéssemos ganho" (RTP, 1975).

Os trabalhadores da Sacor, uma empresa petrolífera, em Maio de 1975, propõem a cedência de fuel e gás a empresas com problemas de ordem económica nas quais se verificou fuga dos patrões e defendem que o controlo operário só terá significado se "levar a um aumento da sua consciência, isto é, se lhes fizer ver cada vez mais claramente quais são os seus verdadeiros interesses e levar a pôr a questão fundamental: a conquista do poder" (ibidem).

O estaleiro naval Setenave, em Setúbal, constitui outro excelente caso de estudo. Os trabalhadores possuem níveis muito elevados de informação (por exemplo, sobre os salários), controle sem resistência de tarefas, reuniões, serviços, pessoal, produção, setor financeiro, chegando ao controlo da função comercial, vital na indústria de construção naval, mantendo um prolongado braço de ferro com as administrações (ROSA et al., 1983, p. 490).

As administrações tentam manter canais institucionais de diálogo abertos, culpando o CTS pela "desorganização" do estaleiro e falta de encomendas, apoiam (também taticamente) as medidas dos governos provisórios, vistos com simpatia por uma grande parte da força de trabalho, jogam com as divisões entre os trabalhadores (extrema-esquerda versus PCP), apelam à lógica "produtivista" e ao "patriotismo".

Enquanto durante 1974 a Administração preocupa-se em salientar a normalidade das relações laborais, a partir de 1975 começa a emitir sinais de preocupação. Em abril, a tentativa de afastamento de um quadro da empresa por parte da CT, conduz à demissão da Administração, dos quadros técnicos e engenheiros. O setor operário recua e a CT apresenta a sua demissão.

Esta crise de impotência revela sintomaticamente uma situação de controlo operário, na qual o contrário das pequenas unidades onde os trabalhadores conhecem melhor os "segredos da produção" e tendem para a autogestão, nas grandes empresas, os operários encontram-se dependentes do saber dos engenheiros e quadros técnicos.

Quando nas empresas, utilizando a terminologia leninista em voga, a base não quer mais viver como outrora e os de cima já não podem viver como antes (LENINE, 1975, p. 16), é o controlo operário que se anuncia, revela. Fenómeno transitório, instável e curto, tal como a situação que o enforma. Que retrograda desvanecendo-se isoladamente, ou avança conservando-se em metamorfose, mudando de qualidade, transformando-se em Estado (FONTES, 2018, p. 61).

\section{Unificação do controlo operário}

Em Portugal verificou-se uma acentuada tendência para a unificação das CTs, mas esse impulso foi por diversas vezes frustrado.

A partir de maio de 1974, cerca de 40 CTs da região de Lisboa e Setúbal, começam a formar uma coordenação relativamente informal, sob a designação de Inter-Empresas, cuja máxima expressão será uma manifestação contra o desemprego e a NATO, que decorre apesar da proibição do governo e um cerco militar, a 7 de fevereiro de 1975 com 80.000 trabalhadores, antes de se eclipsar devorada por conflitos internos entre os diversos partidos de extrema-esquerda participantes.

Os Conselhos Revolucionários de Trabalhadores, Soldados e Marinheiros (CRTSM), inspirados na experiência cubana, tiveram a sua primeira conferência a 19 e 20 de abril de 1975. A iniciativa contou com a participação de trabalhadores de 161 empresas e 21 unidades militares. Contudo acabou por girar quase só à volta do pequeno, mas influente partido de extrema-esquerda que a promoveu, o PRP-BR (Partido Revolucionário do Proletariado-Brigadas Revolucionários), não se constituindo uma projetada "frente soviética". Segundo Pérez (2016, p. 302):

Os CRTSM apareceriam como órgãos políticos da classe no sentido da tomada do poder e a implantação da ditadura do proletariado. É de assinalar a implantação militar desta iniciativa, refletindo a simpatia despertada pelo PRP-BR entre alguns jovens militares, entre os quais Otelo Saraiva de Carvalho.

Por sua vez, o PCP que numa primeira fase tinha criticado as CTs, reorienta a sua tática e reúne 191 CTs na Conferência Nacional Unitária dos Trabalhadores, a 2 de fevereiro. E em junho de 1975 vai criar os Comités de Defesa da Revolução (CDRs). Eram organizações de caráter frentista, como forma de disputar o 
controlo operário nas fábricas e empresas e conduzir a direção deste controlo para formas de cogestão entre sindicatos, trabalhadores e Governo, ou autogestão sob intervenção do Estado.

Os CDRs, com uma implantação assente na cintura industrial de Lisboa, Marinha Grande e algumas zonas do Alentejo tinham como objetivos específicos o apoio e ligação ao MFA e a defesa do plano económico do Governo. Visavam que os trabalhadores tivessem uma preparação militar com vista a impedir os entraves à produção quer este emanasse do controlo operário, quer de formas de sabotagem económica ou descapitalização de empresas.

O I Congresso Nacional das CTs, realizado na Covilhã, a 27 e 28 de setembro de 1975, conta com 53 CTs com direito de voto e 42 observadoras, no qual se defende a coordenação nacional das Comissões de Trabalhadores.

Neste congresso adquire predominância o Movimento Revolucionário do Partido do Proletariado (MRPP), um partido maoista de tipo "mao-spontex" (não reconhecido pela China), estando também presentes pequenas delegações do PS e do Partido Revolucionário dos Trabalhadores (PRT), um pequeno partido trotskysta. Se o PS queria reforçar uma estrutura que fosse contrapeso ao PCP, e por isso apoia esta coordenadora, o MRPP e o PRT, de polos opostos, tinham uma visão mais conselhista do processo.

Os eixos programáticos que saem do congresso são a luta pelas 8 horas diárias, 5 dias por semana, o armamento das CTs em comissões militares, a recusa dos despedimentos e sobretudo, "o desenvolvimento do controlo operário, de toda a produção e distribuição e consumo" (SECRETARIADO NACIONAL DAS CTs, 1975).

A mais importante dessas organizações foi a coordenadora das Comissões de Trabalhadores da Cintura Industrial de Lisboa (CIL) - que foi muito importante nas mobilizações no verão e outono de 1975, agrupando entre duas e três centenas de CTs da capital e que se desdobrou em estruturas regionais semelhantes em Setúbal, Porto e Braga nos meses e anos seguintes.

A CIL, embora com um peso significativo de dirigentes afetos ao PCP, era uma estrutura monolítica dirigida por este partido. Irá convocar várias manifestações com um amplíssimo poder de mobilização, entre setembro e novembro de 1975, apoiadas por quase todos os partidos à esquerda do PS.

Quando se reúnem, pela primeira vez, no Barreiro, a 8 de novembro de 1975, as comissões de trabalhadores da cintura industrial de Lisboa, o PCP advoga uma política de manutenção da produção verificada por uma comissão de controlo da produção que represente todos os setores importantes da empresa; lembrando que havia, naquele momento, 322 mil desempregados, quase 10 vezes mais do que a 25 de Abril de 1974, o PCP considera, no encontro, que "a crise do desemprego não passa pela redução das horas de trabalho", mas sim por uma melhor organização dos trabalhadores, nacionalização do comércio externo e "máximo aproveitamento da capacidade produtiva" (AVANTE!, 1975b).

No seu conjunto, estas medidas permitem criar condições para a reposição da taxa de acumulação por parte dos patrões, medidas que o PCP considera que podem ser aplicadas conjuntamente com a "elevação dos salários dos trabalhadores mais mal pagos" e com a rejeição de indemnizações aos ex-patrões das empresas nacionalizadas. Finalmente, o partido afirma-se frontalmente contra a criação de um organismo nacional de coordenação das comissões de trabalhadores, defendendo que estas devem ter um papel como dinamizadoras das assembleias populares, mas sem qualquer coordenação entre si: "Vemos que a criação dum órgão superior das C.T. institucionalizado e com caráter definitivo poderá trazer o perigo de dispersar esforços, desviando as C.T. dos seus objetivos fundamentais" (ibidem).

A tendência para a unificação das CTs será assim conduzida por diferentes lógicas de aparelho, não se verificando uma frente centralizada capaz de formular uma alternativa orgânica e programática assente nos organismos de democracia do trabalho nas unidades empresariais. A imensa força objetiva do processo de controlo operário, não se sincroniza com uma centralização política.

Contrariamente ao mote insistentemente gritado: "o povo unido, jamais será vencido", a tendência de fundo da revolução portuguesa, progressivamente acentuada à medida que a mesma se prolonga, será a divisão das suas forças. Sintomaticamente, nos dezanove meses de um dos maiores processos revolucionário do século XX, não se declara uma greve geral.

Dezanove meses após o início da revolução, um golpe militar a 25 de novembro de 1975 dirigido por uma frente política que vai dos socialistas até à extrema-direita neutraliza as unidades no exército afetas à chamada "esquerda militar". Esta "contrarrevolução democrática" (FRANCO, 1996, p. 207) consagrará um Estado democrático-representativo de tipo ocidental, com uma constituição que encaminha formalmente a economia ao socialismo, mantendo-se na legalidade os sindicatos, as CTs e partidos de esquerda. Será, contudo, o primeiro passo na derrota do chamado "poder popular", que perdendo o seu "braço armado" vê esvaírem-se as hipóteses de emulação da experiência soviética.

Após o encerramento do período revolucionário, o controlo operário passará a ser designado no léxico governamental como "controlo de gestão". É desta forma que entra na Constituição da República de Abril 
de 1976 , que reconhece no seu artigo $56^{\circ}$, o direito das CTs a "exercer o controlo de gestão nas empresas" (LOPES, 1977, p. 116). Contudo, como refere Sousa Franco (1996, p. 201), foi uma característica não tanto do legado da revolução, mas do próprio período em que esta decorreu. Esvaindo-se "naturalmente" no refluxo pós-revolucionário, as suas reminiscências na Lei Fundamental irão sendo apagadas em sucessivas revisões constitucionais.

\section{Considerações finais}

Como vimos, o controlo operário define-se pela relação antes de mais nada política entre as classes sociais. O controlo é exercido por uma classe sobre outra. Nesse sentido é geral e não particular, ou seja, deve ser compreendido no quadro de um processo revolucionário, enquanto expressão de uma luta política pelo poder de Estado.

Em dezanove meses de revolução, os trabalhadores organizaram-se nas fábricas e empresas em comissões de trabalhadores, os sindicatos foram verticalizados, as comissões de moradores generalizaram-se nos grandes centros urbanos ocupando casas devolutas, os camponeses expropriaram as principais herdades no Sul, as Forças Armadas não conseguiam cumprir a sua função normal repressiva, nem impor a disciplina hierárquica, começando a desagregar-se em diferentes fações. Contudo, estes organismos não chegaram a coordenar-se nem avançaram para formas "soviéticas".

A diferença de ritmos entre a acelerada decomposição do aparelho de Estado e a lenta afirmação de uma alternativa de "baixo" desafia os cientistas sociais a um renovado interesse sobre a configuração do Estado, a dinâmica dos processos revolucionários, e a sociologia das classes sociais, capaz de aportar uma nova luz sobre a conflitualidade social, o papel do político e a morfologia das utopias emancipadoras. Fazer esse caminho, procurou-se demonstrar, pressupõe o estudo do controlo operário, ensaio geral de substituição sociológica do Estado, nas condições excecionais em que este se revela no processo histórico, como na revolução portuguesa de 1974/75.

\section{Referências}

ADLER, M. Conselhos operários e revolução. Coimbra: Centelha, 1976.

AVANTE! Com o PCP pela Unidade Popular Rumo ao Socialismo. Avante! Lisboa, 3 jul. 1975a, p. 4.

AVANTE! Encontro de trabalhadores da Cintura Industrial de Lisboa. Avante! 13 nov. 1975b, p. 5.

BERMEO, N. The revolution within the revolution: workers ' control in rural Portugal. New Jersey: Princeton University Press, 1986. BRINTON, M. Os Bolcheviques e o Controlo Operário. Porto: Afrontamento, 1975.

CASTELEIRO, J. M. (dir.). Dicionário da Língua Portuguesa Contemporânea da Academia das Ciências de Lisboa. Lisboa: Verbo, 2001.

COMISSÃO COORDENAdORA DAS EMPRESAS EM AUTOGESTÃO. A Realidade da Autogestão em Portugal. Lisboa: Perspectivas e Realidades, 1981.

COSTA, A. Setúbal Cidade Vermelha: Sem perguntar ao Estado qual o caminho a tomar. Setúbal: Estuário, 2017.

DIÁRIO DE LISBOA. O poder político passa pela batalha da produção. Diário de Lisboa, Lisboa, 9 maio 1975. p. 1.

FONTES, J. Setenave - Revolução, Nacionalização, Privatização. Lisboa: Parsifal, 2018.

FRANCO, S. A experiência revolucionária (1974-1975). In: REIS, A. (coord.) Portugal, 20 anos de Democracia. Lisboa: Temas e Debates, 1996. p. 176-205.

GRAMSCI, A. Controle Operário. L'Ordine Nuovo, 10 fev. 1921. Disponível em: http://www.marxists.org/portugues/gramsci/1921/ 02/10.htm. Acesso em: 1 jul. 2019.

HAMMOND, J. Worker Control in Portugal: The Revolution and Today. Economic and Industrial Democracy, v. 4, n. 2, p. 413-453, 1981.

HARMAN, C. A People's History of the World. London-Sidney: Bookmarks, 2002.

JAMES, C. L. R. Jacobinos Negros. São Paulo: Boitempo, 2000.

KORSCH, Karl, cit in MARTORANO, L., Conselhos e Democracia. Em busca da participação e da socialização. São Paulo: Expressão Popular, 2011, p. 32.

KORSCH, K. Revolutionary Commune, 1929. Disponível em: https://www.marxists.org/archive/korsch/1929/commune.htm. Acesso em: 3 jul. 2019.

LENINE, V. A falência da II Internacional. Lisboa: Maria da Fonte, 1975.

LENINE, V. O Controlo Operário e a Nacionalização da Indústria. Lisboa: Estampa, 1976.

LOPES, V. S. (org.). Constituição da República Portuguesa 1976 (anotada). Lisboa: Centro do Livro Brasileiro, 1977. 
MANDEL, E. (ed.). Contrôle Ouvrier, Conseils Ouvriers, Autogestion. Paris: François Maspero, 1975.

MARX, K. A Guerra Civil na França. São Paulo: Boitempo, 2011.

MATTICK, P. Integração capitalista e ruptura operária. Porto: A regra do jogo, 1977.

PANNEKOEK, A. Letter on Workers Councils, 1952. Disponível em: https://www.marxists.org/archive/pannekoe/1952/lettercouncils.htm. Acesso em: 1 jul. 2019.

PANNEKOEK, A. Los Consejos obreros. Bilbao: Zero, 1977.

PATRIARCA, F. Controlo Operário em Portugal (I). Análise Social, v. XII, n. 47, 1976a. p. 765-816.

PATRIARCA, F. Controlo Operário em Portugal (II). Análise Social, v. XII, n. 48, 1976b. p. 1056-1057.

PÉREZ, M. Conselhos Revolucionários de Trabalhadores, Soldados e Marinheiros. In: REIS, A. et al. (coord.) Dicionário de História de Portugal: O 25 de Abril. Porto: Figueirinhas, 2016. p. 302-303.

ROSA, E. A Economia Portuguesa em Números. Lisboa: Moraes, 1975.

ROSA, T. et al. Sistemas de Trabalho, Consciência e Ação Operária na Setenave. (Dissertação de Licenciatura)-Instituto Universitário de Lisboa, Lisboa, 1983.

RTP. Noticiário Nacional. 30 jun. 1975. Arquivo da RTP. Bilbao: Zero, 1977.

SECRETARIADO NACIONAL DAS CTs. Viva o $1^{\circ}$ Congresso Nacional das Comissões de Trabalhadores. Viva a Classe Operária, 10 out. 1975. p. 1.

TROTSKY, L. História da Revolução Russa. Rio de Janeiro: Paz e Terra, 1980.

TROTSKY, L. Workers Control of Production: Letter to a group of German Left Oppositionists, 1931. Disponível em: http:// www.marxists.org/archive/trotsky/germany/1931/310820.htm. Acesso em: 2 jul. 2019.

WINN, P. Weavers of Revolution: The Yarur Workers and Chile's Road to Socialism. New York: Oxford University Press, 1986.

ZINN, H. A People's History of the United States. New York: Harper Perennial, 2005.

\section{Raquel Varela}

raquel_cardeira_varela@yahoo.co.uk

Doutora em História Política e Institucional pelo Instituto Universitário de Lisboa (ISCTE)

Coordenadora do Grupo de História Global do Trabalho e dos Conflitos Sociais, Instituto de História Contemporânea, Universidade Nova de Lisboa (IHC- FCSH-UNL)

\section{IHC}

Avenida de Berna, $26 \mathrm{C}$

Lisboa-Portugal

CEP: 1069-061

\section{Jorge Fontes}

fontes.jorge@gmail.com

Doutor em História pela Universidade Nova de Lisboa (UNL)

Pesquisador no Instituto de História Contemporânea (IHC- FCSH-UNL)

\section{IHC}

Avenida de Berna, 26 C

Lisboa-Portugal

CEP: 1069-061

\section{Agradecimentos}

Não se aplica.

\section{Agência financiadora}

Não se aplica.

\section{Contribuições das autoras}

Raquel Varela foi responsável pela maior parte do conteúdo em

"Os debates sobre o controlo operário" e "Evolução do controlo operário". Os subcapítulos "Casos de estudo" e "Unificação do controlo operário" tiveram uma contribuição equivalente. Jorge Fontes foi responsável pela maior parte do conteúdo em "Introdução" e "Considerações finais", fez o resumo, referências bibliográficas, organizou o artigo e procedeu à sua revisão, adequação a normas da revista e submissão eletrónica. 
Aprovação por Comitê de Ética e consentimento para participação

Não se aplica.

Consentimento para publicação

Consentimento dos autores.
Conflito de interesses

Não há conflito de interesses. 